\title{
Effects of Teaching Critical Thinking to Saudi Female University Students Using a Stand-Alone Course
}

\author{
Amani K. Hamdan Al Ghamdi ${ }^{1} \&$ Philline M. Deraney ${ }^{2}$ \\ ${ }^{1}$ College of Education, University of Dammam, Dammam, Saudi Arabia \\ ${ }^{2}$ Preparatory Year \& Supporting Studies, University of Dammam, Dammam, Saudi Arabia \\ Correspondence: Amani K. Hamdan Al Ghamdi, Assistant Professor Curriculum and Pedagogy, College of \\ Education, University of Dammam, Dammam, Saudi Arabia. E-mail: akhalghamdi@ud.edu.sa
}

\author{
Received: May 10, 2013 Accepted: June 17, $2013 \quad$ Online Published: June 24, 2013 \\ doi:10.5539/ies.v6n7p176 URL: http://dx.doi.org/10.5539/ies.v6n7p176
}

\begin{abstract}
Teaching critical thinking, an educational goal widely discussed in the last 30 years (Halpern, 1993), is an essential element of professional and higher education as it promotes reasoned judgments under 'conditions of uncertainty,' a hallmark of professionalism (Levine, 2010; Shulman, 2005; Perry, 1970). In this study, the researchers present the implications of teaching $\mathrm{CT}$ in a course format in a Saudi private university that is preparing female professionals for the workforce. The course is taught as part of the general education requirements in the freshman year of study. Female students in the fields of business, computer sciences, and interior design participated in a CT pre-test /post-test sequence given at strategic times throughout the semester. The data illustrate significant improvement in the area of argument identification and analysis, but moderate to low improvement in the other markers of critical thinking. The results not only reflect course instruction as well as other external factors. The study suggests and recommends that in order for students to be critical thinkers, critical thinking would ideally be embedded or integrated throughout the students' academic career, not just in one, stand-alone course.
\end{abstract}

Keywords: critical thinking, female students, Saudi Arabia, NCTT instrument, infused, stand-alone

\section{Introduction}

Critical thinking (CT here on) has gained heightened attention in higher education. Indeed, teaching CT, an educational goal widely discussed in the last 30 years (Halpern, 1993), is an essential element of professional and higher education as it promotes reasoned judgments under 'conditions of uncertainty,' a hallmark of professionalism (Shulman, 2005; Perry, 1970).

In this study, the researchers present the implications of teaching CT in a course format in a Saudi private university that is preparing female professionals for the workforce. The course is taught as part of the general education requirements in the freshman year of study. Female students in the fields of business, computer sciences, and interior design participated in a CT pre-test /post-test sequence given at strategic times throughout the semester. During the 16 weeks of classes to improve CT skills, students covered topics such as the structure of an argument, reasoning errors, inductive and deductive arguments, arguments based in authority, example, and analogy and cause/effect. The researchers found that although the students overall CT skills seemingly improved according to the pre-and post-tests, CT skills require more than a course. Further study, consideration of various factors, and a strong willingness and obvious role on the part of the college student are also key factors (El Hassan \& Madhum, 2007; Stratton, 1999).

CT has been considered as a paramount aspect of skills that higher education should consider when preparing students in their first year at university, "CT is a paradigmatic case. Universities insist that CT is a requirement of quality academic work while academics bemoan the lack of a critical approach" (Egege \& Kutieleh, 2004, p .75). For students to be critical thinkers and to be able to infuse CT as part of the way they perceive the world, it must be embedded in all courses throughout the four-year bachelor program.

This study analyzes the progression (via pre-test/post-test) of female undergraduate students who enrolled in a required CT (CT) course in Spring 2011 at a private university in Saudi Arabia. Specifically, the research examines the complicated issue of whether or not a CT course (stand-alone) is of substantial benefit to the 
students (i.e. illustrates marked improvement) based on the pre-test/post-test skills tested. First, a brief background on CT and the course are presented followed by the methodology used, the results and discussion, and finally possible implications for future research.

\subsection{What is Critical Thinking?}

CT has been defined in various ways and by a variety of researchers. One of the definitions is that CT is "reflection, identification and appraisal of assumptions inquiry, interpretation, and analysis and reasoning and judgment with the consideration of context" (Choy \& Cheah, 2009, p.198). Our definition agrees with that of the National Council for Excellence in CT Instruction (NCECTI) (Scriven \& Paul, 2003), CT is "the intellectually disciplined process of actively and skillfully conceptualizing, applying, analyzing, synthesizing or evaluating information gathered from or generated by, observation, experience, reflection, reasoning, or communication as a guide to belief or action" (p.34). Another definition by Halpern, (1997) is that it is viewed as purposeful, involving "the use of those cognitive skills or strategies that increase the probability of a desirable outcome" or as "the process of analyzing, evaluating and synthesizing information in order to increase our understanding and knowledge of reality" (Sievers, 2001, p. 12). Various studies highlighted the significance of CT in higher education. In one study, Egege \& Kutieleh, (2004) argued that:

Although CT has always been viewed as a necessary attribute of all successful tertiary students, there has been an increasing emphasis in recent years on the overt acquisition or teaching of CT skills, with most academic disciplines now making this requirement explicit. There is no longer an assumption that students will acquire the skill in the normal course of their academic degree. Subject topics specify the need for a critical approach or evidence of CT by including the role of critique, critical reflection, or critical analysis in their course outlines. Essay questions clearly state that critical analysis and evaluation will be a part of their grading (p.76).

\subsection{Critical Thinking: Infused vs. Stand-Alone}

After reviewing the literature about infused CT or stand-alone course, such as the one offered at the university in which we applied the study pre and post-tests, we conclude that in general there are two ways to consider CT: a stand-alone course or contextualized CT into existing studies or activities. In some university courses where CT is taught as a stand-alone course, it is typically within more general academic skills programs (see, for example, Tapper, 2004; van Gelder, 2000 as cited in Lloyd \& Bahr, 2010). However, in contextualized studies, these courses have been developed because of presumed low levels of CT among tertiary students (Guest, 2000; van Gelder, 2005 as cited in Lloyd \& Bahr, 2010). The stand-alone option is challenged by criticism of CT as a "free-floating entity" (Moore, 2004); a contention which has implications for the potential to either teach or test it out of context (Lloyd \& Bahr, 2010). Yet, as Hatcher's study indicates, an integrated approach to teaching CT "yields greater pre- to post-test gains on a variety of standardized CT tests than a typical stand-alone CT/informal logic course" (Hatcher, 2006, p. 248). McPeck (1981, p. 5) is highly critical of the typical stand-alone informal logic/critical thinking course and recommends an integrated approach that is discipline specific. Rather than a stand-alone required CT course, students should learn what it means to think critically in the specific academic areas.

However, Peter Facione (1990, 1986 as cited in Hatcher, 2006) and Harvey Siegel (1988 as cited in Hatcher, 2006) conclude that there are generic critical thinking skills that transcend specific disciplines and can be applied throughout academia (Facione, 1990). Further, a study by Levine (2010) which focuses on how teaching critical and divergent thinking are integrated in social studies course for in service teachers emphasizes the point of CT across the disciplines. The researcher indicates that "Socialization contrasts with critical thinking, which aims to develop individuals who engage in questioning, evidence seeking, and reasoning rather than passively accepting facts and conclusions" (p. 69). This is an important requirement of today's students across disciplines and professions. It seems that for $21^{\text {st }}$ century skills critical thinking is mandatory and not a luxury (Paul\& Elder, 2002, p.5).

This study examines how students employ CT skills after attending and passing a stand-alone course at university. The researchers concur with Elder's (2001) emphasis that a major facet of CT involves examining assumptions that underlie thoughts and actions, experiences, and values, which are related to the main concepts of the course. This study will explore and confirm which side offers more positive long-term change in students' critical thinking abilities. After all,

Given the recent studies assessing the outcomes of integrated approaches compared with stand-alone approaches, it seems fair to say that integrating instruction in critical thinking either with instruction in a 
discipline, for example, psychology, or with instruction in other generic skills such as writing is superior to trying to teach logical skills in a standard CT or logic course. (Hatcher, 2006, p.269)

\subsection{Critical Thinking in Saudi Arabia}

For the last decade Saudi education has been subject to a great deal of criticism for its lack of focus on CT and problem solving and overemphasis on memorization. Education in Saudi Arabia has been didactic instruction in all fields K-12 and higher education alike. Yet the recent years have witnessed major development and reform in education led by the Saudi King Abdullah Ibn Abdulaziz.

Upon reviewing the literature on $\mathrm{CT}$, it is noted that until recently Saudi tertiary education has lacked a focus on CT and problem solving (PS here on). There is still more attention towards memorizing and less on inquiry-based learning. John Goodlad (1984), in extensive research in secondary schools, found that Saudi textbooks were often a substitute for pedagogy that teaching methods tend to be mechanistic and engaging, and that memorization and rote learning were favored consistently over creativity and CT. Richmond (2007) wrote that in developing countries, "The educational methods commonly used in developing countries, particularly rote learning by students expected to be passive recipients of knowledge, are mostly ineffective at training professionals to think critically and creatively about the development needs of their nations" (p. 1).

In a similar way, Larry Cuban (1993) concluded that teacher or subject-centered instruction has been for the most part the basic form of instruction "in spite of progressive educational movements to promote student-centered teaching” (Nieto, 1999, p. 77). CT starts in classrooms that are student-centered and encourages questioning and inquiry-based learning.

Because of the need to develop CT and PS skills as required skills for the labor market, Saudi universities started to implement courses such as CT (AlWehaibi, 2011), professional development, ethics in the profession, and leadership. In fact, the course has been introduced recently - in the past 4 years mostly in private universities and some colleges across the Kingdom that adopted Western-developed curricula following what seems to be a world trend. In the university where the research was conducted, six competencies, including critical thinking and problem solving, are among the primary goals for graduation, and $\mathrm{CT}$ is part of the setting to prepare students for their specialty courses.

\subsection{Course Context: CT and Problem Solving}

The course itself, CT and Problem Solving, is a key element of the research. The course used in the study offers the students an awareness of their own thought processes (metacognition), advances their current skills, and introduces additional CT skills. The course is a stand-alone CT course that is taken typically in the second semester of the first year of the undergraduate program (second-semester freshman). It is a requirement for graduation in all majors and is part of the university's general education courses (called Core Curriculum), which represents one of six university core competencies; therefore, the class is highly structured and has a common syllabus shared by all instructors, male and female.

$\mathrm{CT}$ is the second course of a 3-course series designed specifically to develop professional and academic skills. The other two courses focus on professionalism, setting goals, considering a career path, leadership styles, and teamwork and actually cover similar material. The CT course focuses on the subject from an academic standpoint emphasizing argumentation, which comprises about $58 \%$ of the topics covered (see Table 1 below). The students complete four assessments to create and identify arguments and fallacies and present logical discussions based on sound and valid argumentation. It is a 2-credit course in the students' 125-136 credit-hour degree plan (final credits required vary depending upon major). The course is given two hours per week in a 16 -week semester for a total of about 26 hours of actual instruction time. The remaining time is for student presentations, a midterm, and a final exam. 
Table 1. Course Topics* and Coverage Time**

\begin{tabular}{lll}
\hline No. & Topic & $\begin{array}{l}\text { Coverage } \\
\text { Time/Hours }\end{array}$ \\
\hline 1 & What is CT & 2 \\
2 & Attributes of a Critical Thinker & 1 \\
3 & Argument Definition and Structure & 2 \\
4 & Reasoning Errors/Fallacies & 2 \\
5 & Composing A Short Argument & 1 \\
6 & Arguments by Analogy, Example, and Authority & 2 \\
7 & Reality and Value Assumptions & 2 \\
8 & Deductive Reasoning & 2 \\
9 & Inductive Reasoning/Arguments; Causal Generalizations and & 2 \\
& Analogies & 2 \\
10 & Arguments about causes; cause and effect & 2 \\
11 & Values and Ethics in CT & 2 \\
12 & Power of Language in CT & 2 \\
13 & Fair Mindedness and Avoiding Emotional Reasoning & 2 \\
14 & Problem Solving and Decision Making &
\end{tabular}

* Listed in order of coverage

**Slight coverage time variation dependent on instructor

\section{Method}

\subsection{Participants}

A total of 118 female students (total course population; aged 18-24; average age of 19) majoring in eight different fields (in the areas of business, computer science, and interior design) enrolled in the required CT course and were therefore eligible for participation; about $60 \%$ were business majors. Of the total, 98 students took the pre-test and 56 took the post-test, $47 \%$ of the total enrolled students. The typical student in this course is a freshman in the first year of undergraduate studies who has completed 15 credit hours and has spent 1-2 semesters in the university's preparatory program. Both male and female students take the course; however, the study was conducted with female participants only as the classes (as the entire university) are gender-separated and the researchers have immediate access to the female student population only. The preparatory program (also called the foundation year), common in universities in the region, offers courses in English language, mathematics, and study skills all instructed in the English language.

Of the participants, $96 \%$ were Saudi nationals with an L1 of Arabic. The remaining $4 \%$ represent other nationalities (majority with an L1 of Arabic) with only $2 \%$ of the students having an L1 other than Arabic, i.e. Urdu, English. As per the admission requirements of the university (IELTS level 5.0 or equivalent), all students have English proficiency but varying levels of advanced English skills. Nearly three-quarters or $75 \%$ of the students who took the course studied in the 'science' stream of secondary school, which focuses on skills required for the natural sciences and mathematics courses. Additionally, while only $10 \%$ of school-age Saudi nationals attend private schools (Al-Seghayer, 2011), at this private university, nearly $60 \%$ of the enrolled female students graduated from private secondary education. This is an important factor as private-educated students in Saudi Arabia have had varying degrees of exposure, some quite substantial, to the English language beginning in the first grade. As the study was conducted entirely in English, language would prove to be an important mediating variable in the students' responses.

\subsection{Instrument}

The pre/post instrument used was the NCTT (National Center for Teaching Thinking, 2009) Assessment Instrument, Saudi Arabian Version 3 developed by Dr. Robert Swartz and a team of educators. This instrument, under development for more than two decades and based on actual classroom practices and teacher feedback, 
emphasizes extended response (ER) rather than the traditional multiple choice as an assessment of critical thinking (Swartz, 2011).

Further, this exam, compared to other CT exams (the Cornell Critical Thinking Test, Watson-Glaser Appraisal, etc.), has been used extensively in Saudi Arabia over the last few years. Considering the linguistic background of the students (L1 of Arabic), when tested in English particularly, extended response actually allows the students to explain and therefore demonstrate their critical thinking skills in a manner that MCQs may not allow. Further, several of the situations in the assessment are culturally appropriate and bring forth examples and situations that are accessible to Saudi Arabian students.

The NCTT instrument used in this research assesses four areas of critical thinking: reliability of sources, prediction of future events, causal explanation, and argument analysis and assessment. Fourteen items/situations were on the exam with extended response and, in some cases, multiple choice questions after each item.

\subsection{Research Design}

All 118 female students enrolled in the Critical Thinking and Problem Solving course (5 sections total; 2 instructors) were eligible and asked to participate. Participation was voluntary and confidential and based on the criteria of being enrolled in the course and female. The entire course population was invited to participate; there were no marks attached to participation.

The pre/post tests were given in weeks 7 and 15 respectively of the 16-week course. The pre-test was administered in week 7 , as the course did not begin until week 2 , the concept of critical thinking and related terminology is entirely new to these students and therefore the baseline of the pre-test, if given in week 2, may have been inaccurately low. Therefore, the timing (mid and late semester) of the pre/post tests would provide a more accurate comparison between the participants' CT skills between midterms and finals. The participants were given up to two hours to complete each of the exams with the majority spending 1.25 to 1.5 hours to complete the exam. The exams were then coded by the researchers and assessed and analyzed by the National Center for Teaching Thinking (the source of the instrument) for valid results. One trained evaluator assessed all of the results based on the NCTT instrument's scoring rubric (Swartz, 2011). As there was a large decrease from pre-test to post-test in number of participants (98 to 56 which still represented $47 \%$ of the total enrolled), all exams were analyzed, but no significant difference was found between the initial participants and the final post participants. Therefore, the results are based on the 56 participants' pre/post assessments.

\section{Results}

The results section is based on the actual pre/post test data analysis and report from the National Center for Teaching Thinking with further analysis and discussion from the researchers based on the data analysis, the course and participants in relation to the research, and critical thinking realities in the region in general.

\subsection{Overall Results}

The data analysis, based on a scale from 1-5 (highest), indicated that the students scored a 2.3 or below in all areas (2.0 average from post-test) out of 5.0. Although the overall results were considered low according to the instrument's scale (which is expected based on the students' background with CT in their previous experiences), the assessment also demonstrated that students improved slightly in all areas of critical thinking with a significant increase in argument analysis and moderate increase in prediction of future events with evidence (Figure 1). Further, of 784 total test items from the sample size, 250 items were 'skipped' or not answered in the pre-test and 158 items in the post-test, which shows a 37\% decrease. This improvement from pre to post is noteworthy and shows the ability and potential to increase skills, confidence in critical thinking abilities, and perhaps even maturity and improved English skills within a concentrated short period of time. 


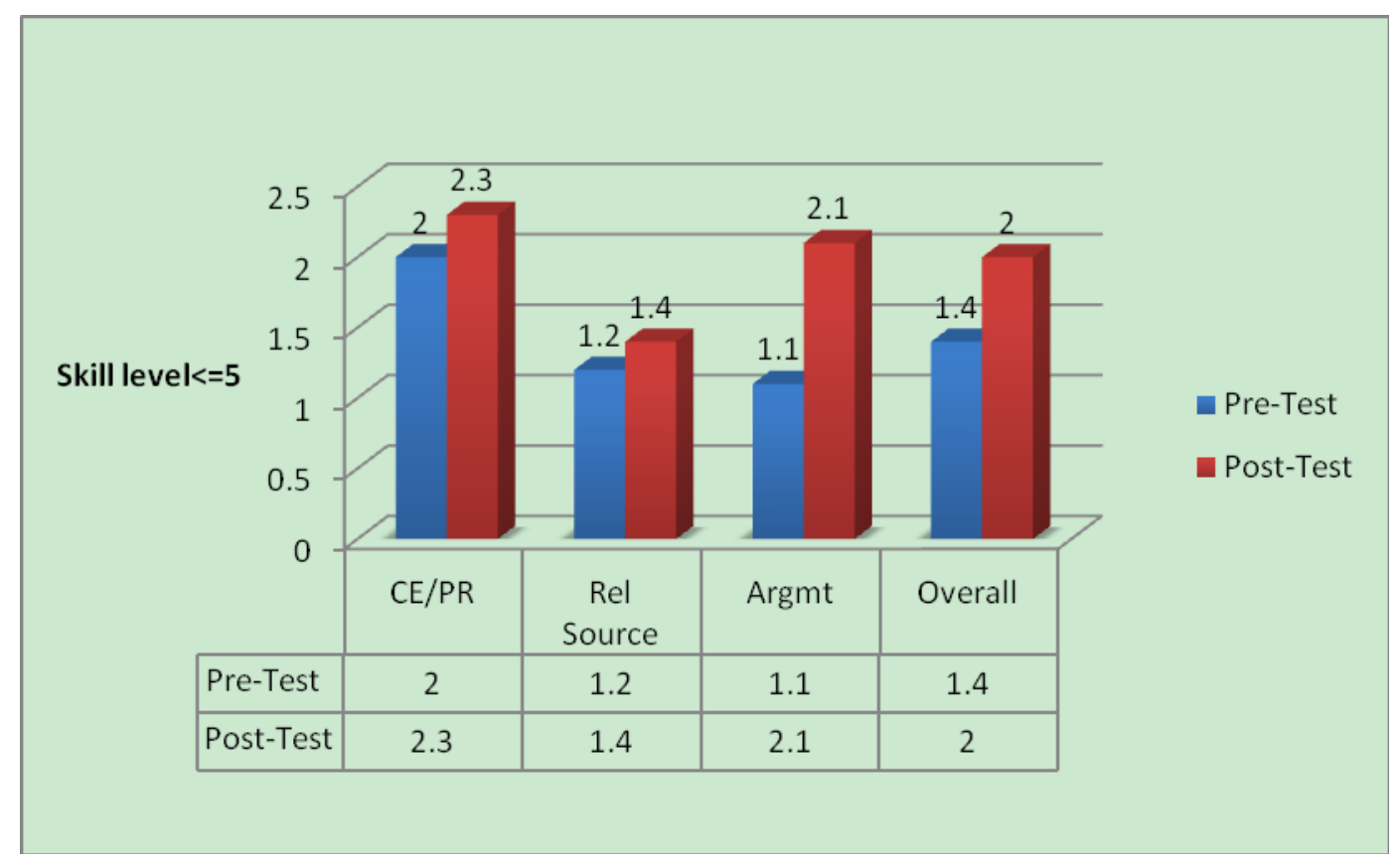

Figure 1. Overall results from pre to post test in the four tested areas of critical thinking

Figure adapted from Swartz, R. (2011). Dammam Critical Thinking Study 2011. National Center for Teaching Thinking.

\subsection{Argument Analysis and Assessment}

The area that showed the most marked improvement was argument analysis, specifically analysis and evaluation of arguments and identifying and evaluating arguments. As shown by the data, in the area of analysis and evaluation (Figure 2), the number of participants who 'skipped' items went down $56 \%$. Similarly, several participants showed improvement in the weak, moderate, and high levels of argument analysis and evaluation skill with increases from 5 to 13 (260\% increase), 6-9 (50\% increase), and 1-2 (100\% increase) respectively. However, although the increase is significant, $25 \%$ of the participants still skipped some items. No students showed 'no skill' or 0 level of performance on these items.

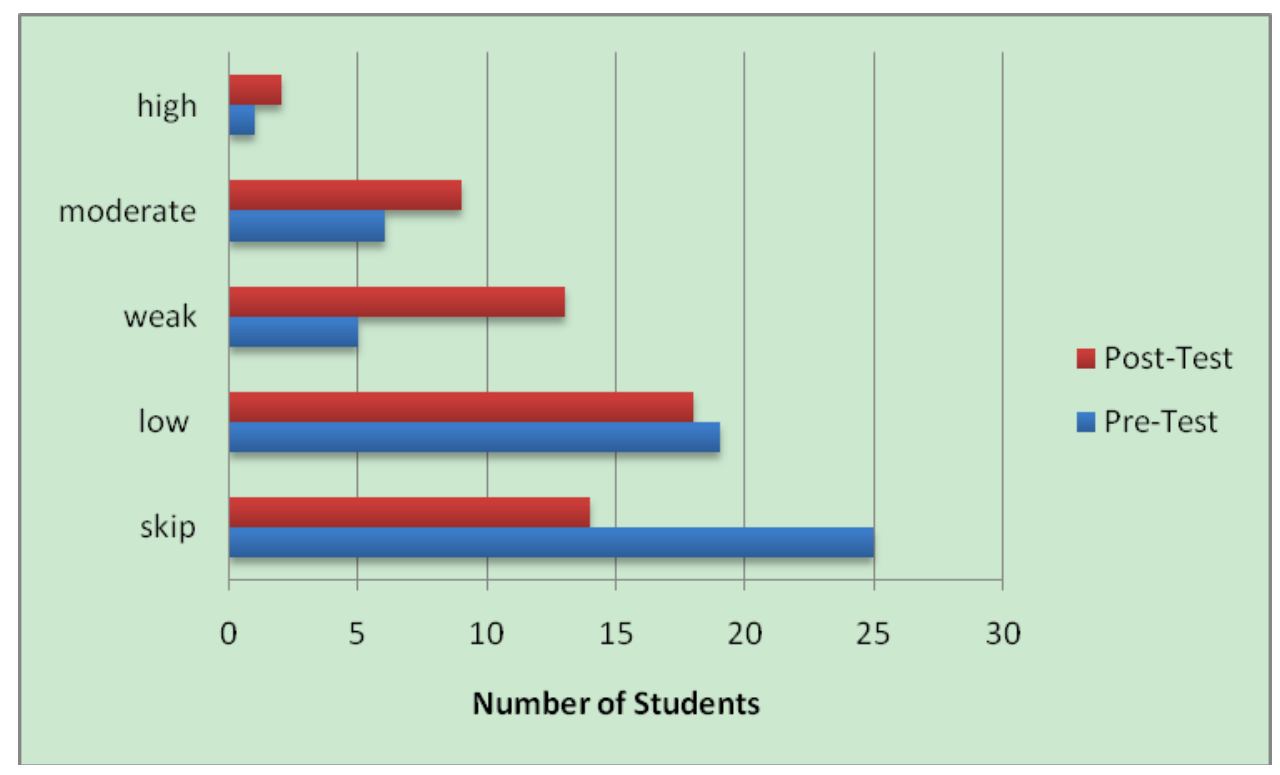

Figure 2. Argument analysis and evaluation 
This figure illustrates the pre to post-test change in the area of argument analysis and evaluation.

Figure 3 illustrates the improvement in identifying and evaluating arguments. The weak (3) category increased from 2 to 12 participants and 2 students increased in the moderate category. It is notable that no students achieved the high (5) category in identifying and evaluating arguments.

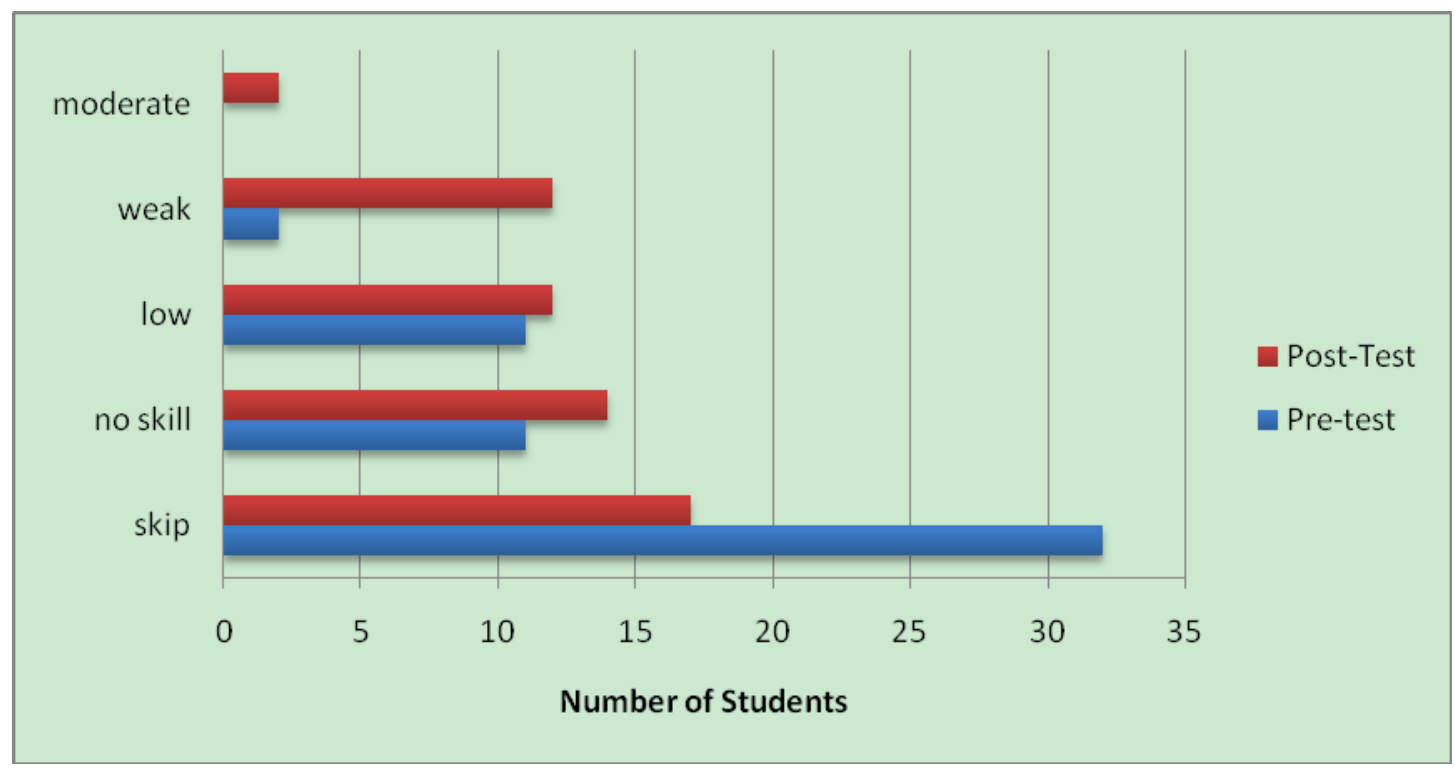

Figure 3. Identifying and evaluating arguments

This figure illustrates the change from pre to post test in the skill of identifying and evaluating arguments.

The significant improvement in argument analysis and evaluation coincides and likely consequently results from the fact that 11 hours average (slight variance based on instruction and class) or $46 \%$ of the instruction time in the course is based on argument identification, analysis, and evaluation. Additionally, three of the four graded assignments are based in argumentation: identifying arguments, faulty reasoning, and analyzing arguments via a debate format both written and spoken - the last assignment which includes some argument evaluation receives the least amount of instructional time which also coincides with the data. The participants improved significantly in identification and analysis, but not in evaluation, a higher-level CT skill.

\subsection{Causal Explanation}

The second most notable, but not significant, area of improvement in causal explanation/prediction skills assessed causal reasoning, causal explanation and evidence, and possible hypotheses to explain events. The participants went from 2.0 to 2.3 pre to post-test suggesting a move from low to low-weak skill level. Most areas did not show marked improvement such as the areas of seeking or judging evidence, for/against, to explain events, but two areas did show improvement that most likely can be connected to the exact coverage in the course.

Figure 4 illustrates that the participants were able to improve their ability to hypothesize about a cause with given evidence, even weak evidence. This improvement not only in skills but confidence level shown by a $1 / 3$ drop in 'skipped' answers and an improvement in the 'no skill,' 'weak,' and 'moderate' skill categories by 6, 7, and 4 participants respectively shows a definite gain in that area of causal explanation critical thinking. 


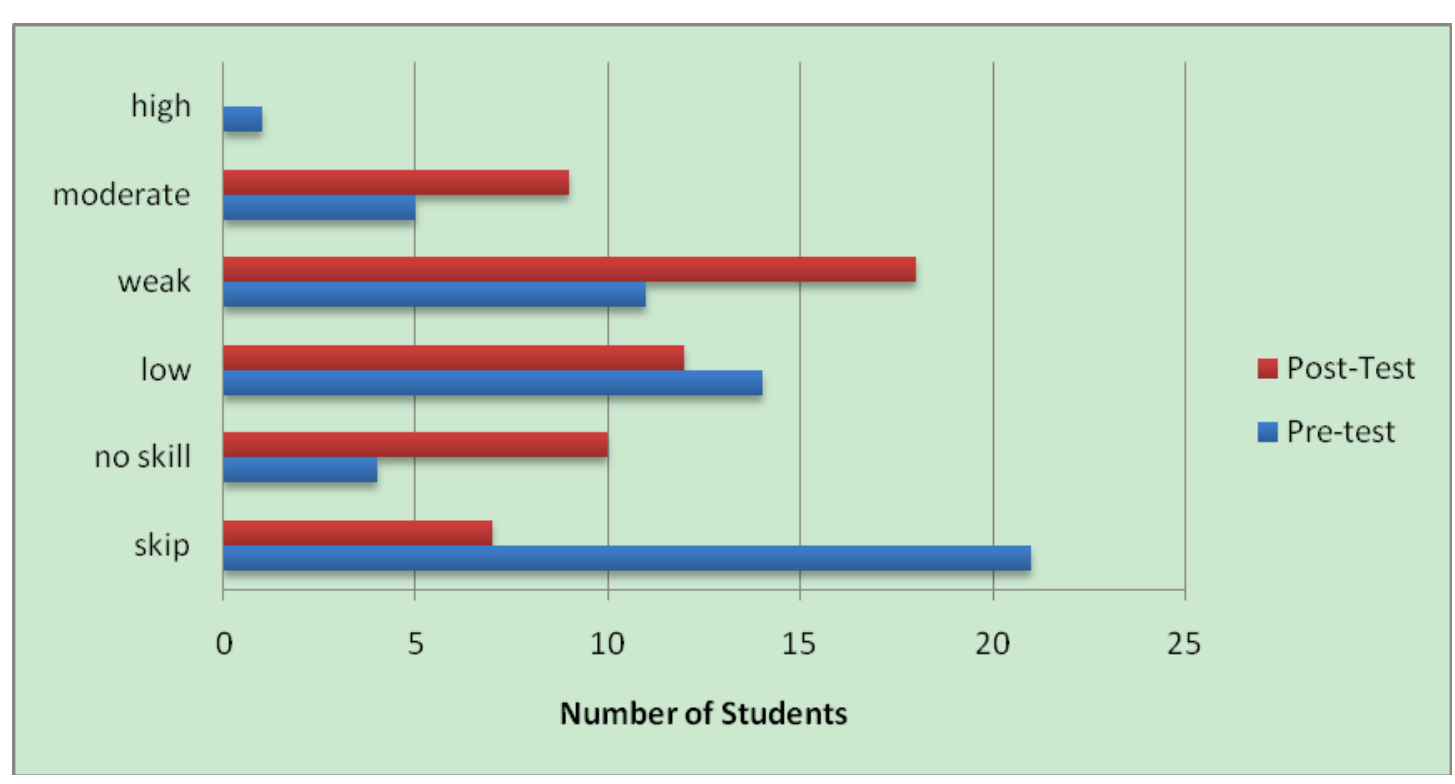

Figure 4. Causal explanation

This figure illustrates the change from pre to post test in the skill of causal explanation.

This result coincides with the class instruction in this skill as per the course instructors and syllabus. The students were given arguments and cases, ethical and practical in the fields of business, engineering and information technology, with weak and strong evidence and asked which possible conclusion or hypothesis it supported - to make a prediction in a sense. Due to the fact that the students were not skilled at or previously taught critical thinking skills, the presentation of evidence and then 'matched' to a hypothesis was more reasonable and perhaps easier than being given a hypothesis and then asked to identify appropriate evidence.

\subsection{Prediction of Future Events}

The pre-test/post-test included a prediction item that asks the participants to judge between evidence and a possible hypothesis as a predictor (Swartz, 2011). Again, the students did well on this item with given evidence. Figure 5 illustrates the improvement with nearly one-half of the skipped items pre to post test, and increases in participant skills in the low, weak and moderate categories.

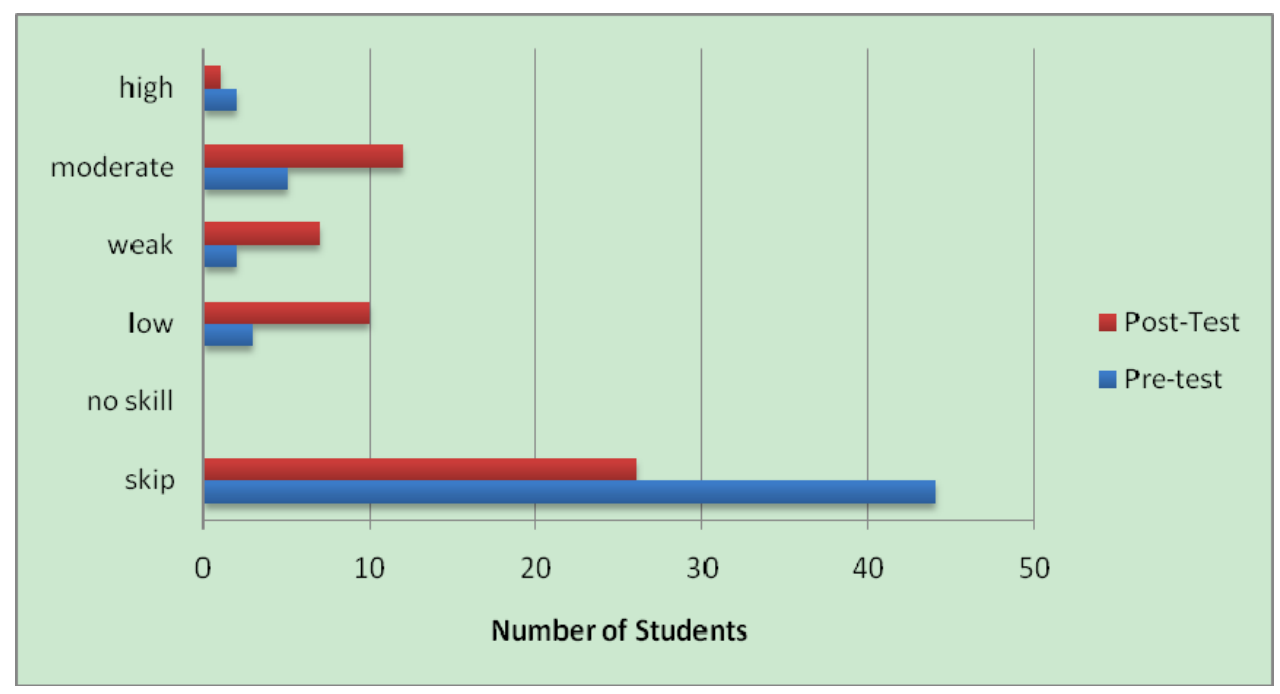

Figure 5. Prediction with evidence

This figure illustrates the pre to post-test change in the area of prediction with given evidence. 
The notable improvement in some areas of causal explanation and prediction could be attributed to not only the argumentation instruction which emphasizes logical flow of arguments and faulty reasoning, but the remainder of the course which involves case dilemmas, problem solving, and decision making often based on ethical schools of thought and identifying reasoning errors. Further, the participants typically take a 'sister' course at the same time focused on research skills and are required to produce a research-based project which involves making predictions supported by evidence. However notable, the lack of significance in movement suggests that the course does not go in enough depth in the areas of causal explanations and emphasizes prediction with given evidence but not logical, possible causes.

\subsection{Reliability of Sources}

The weakest area or the area in which no marked improvement was shown was in the key area of reliability of sources. The assessment asks the participants to judge reliable sources in the forms of written, people, observers, and self-observation. NCTT instrument developer Robert Swartz (2011) wrote, "It is through judging the reliability of sources of information that much of the information we accept and use in inferences is obtained" (p. 15) and reliability of sources is often a skill that must be taught to produce a 'significant' level. Unfortunately, the participants only improved slightly, 1.2 to 1.4 average, from pre to post test, which is in the category of 'no skill' to 'low' skill.

Of the four areas of reliable source judgment, the two that showed some improvement were in judging the reliability of sources for 'people' with expertise and the participant herself - 'yourself as observer.' Figure 6 illustrates the slight improvement in the low, weak, and moderate skill levels in the judging the reliability of people as sources. The confidence of the participants in this area is notable as few skipped items. However, the lack of real improvement in this skill shows a major deficiency or lack of ability to not only judge reliable sources, but also consequently reliable and worthy information, which strongly affects ethical, informed, and responsible decision-making.

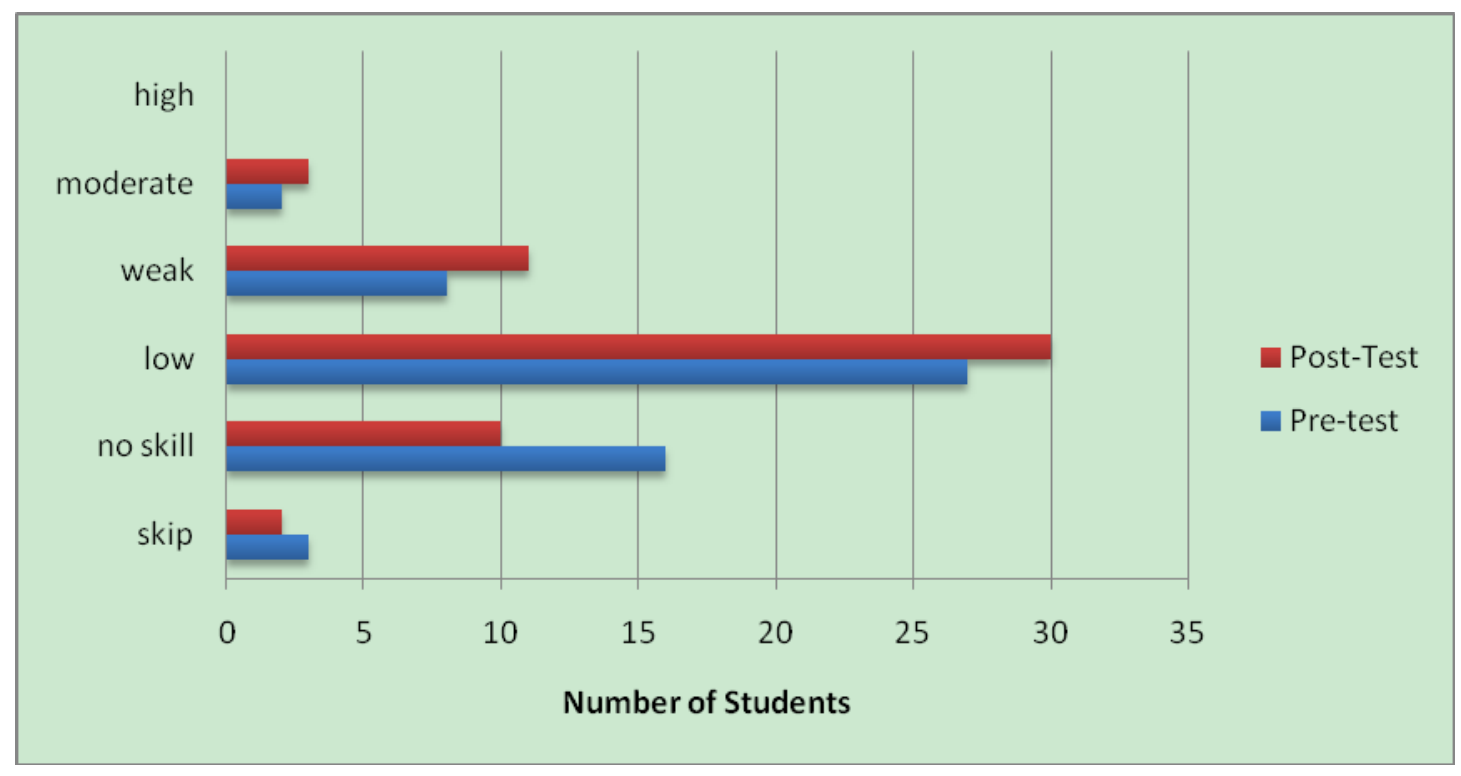

Figure 6. Reliability of sources (people as experts)

This figure illustrates the change from pre to post- test in the participants' judgment of people (experts) as reliable sources.

The participants showed the most improvement in judging the reliability of self as observer. The low, weak, and moderate categories improvement slightly and the number of skipped items reduced by 16. However, 26 skipped items, or nearly half of the sample is still high and shows lack of either ability or confidence in this skill. 


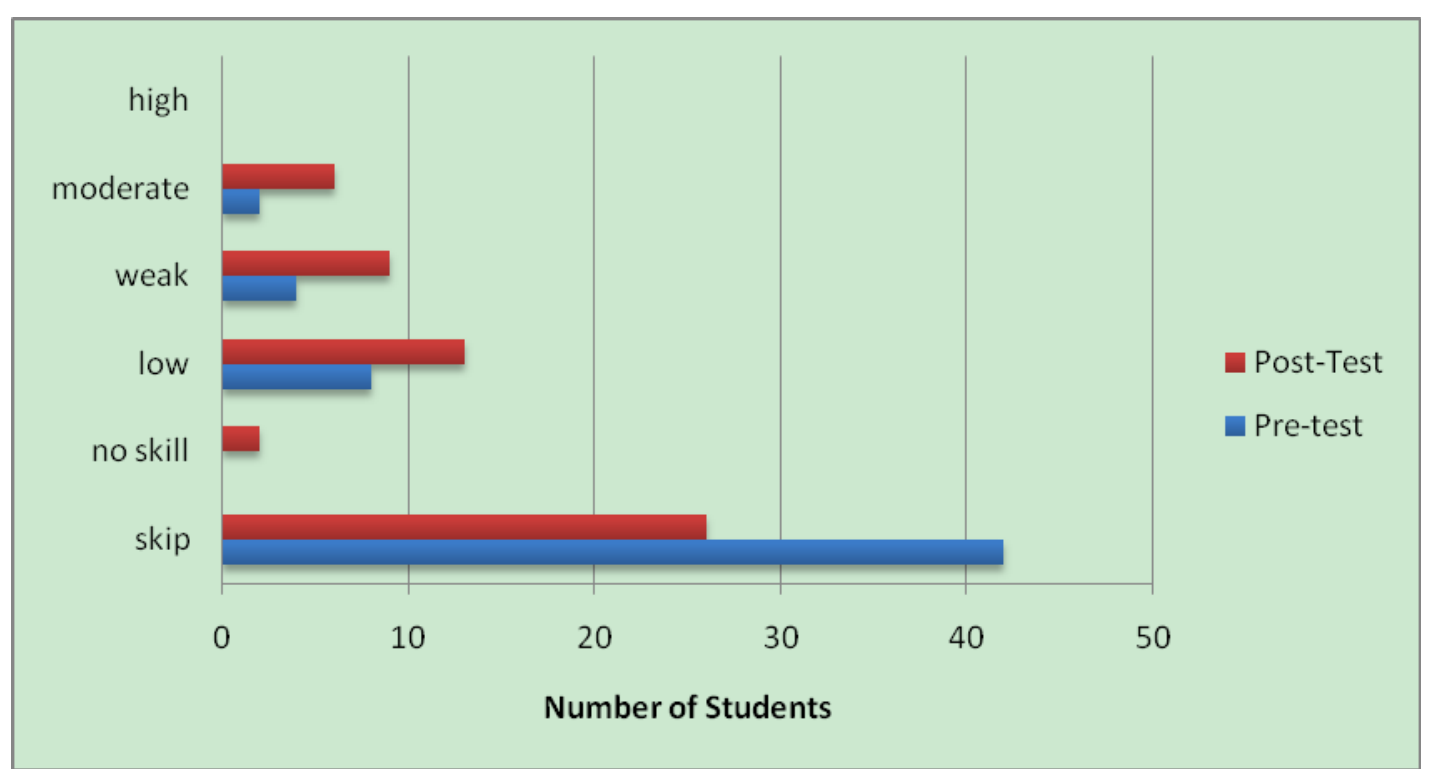

Figure 7. Reliability of sources (self as observer)

This figure illustrates the change from pre to post-test in the area of 'self as observer' as reliable sources. In the reliability of sources CT area, 'self as observer' showed the most marked, yet insignificant, improvement.

The overall poor performance in the area of reliability of sources shows the willingness of the participants to accept information without critical observation or evaluation. The course itself does not emphasize this skill as shown in the course instruction breakdown; however, its 'sister course,' Writing and Research, emphasizes research with a moderate focus on sources, how to identify, evaluate the reliability, and annotate the key information. It's obvious from the data that this is an area that needs more attention not just for the participants' academic careers, but also for far-reaching reliable and ethical decision-making.

\section{Discussion and Implications}

Although this research cannot be generalized to other universities or other regions, this pre/post-test sequence suggests that critical thinking cannot be taught and provide significant results in a single course. The results concur with the idea that CT should be consciously and explicitly integrated throughout the students' academic careers at both the K-12 and tertiary levels. A stand-alone course, although effective in showing some improvement and highlighting the critical thinking skill, cannot prepare the students for all of the areas needed in true and trained critical thinking. This point is illustrated by the fact that in Spring 2011, of the 118 total females registered, 58 (49\%) fulfilled the requirements for a grade of $\mathrm{A} / \mathrm{A}^{+}, 30(25 \%)$ earned a $\mathrm{B} / \mathrm{B}+$, and the majority of the remaining earned a $\mathrm{C} / \mathrm{C}+$. The final grades are an important and in this case a negative indication that earned marks in a course do not equal actual CT success or improvement. The marks show success in the course requirements, a common syllabus for and created from a North American CT course (using North American textbooks), which, in this case, do not parallel the results of the overall CT skills assessment.

Furthermore, the research and students' course results suggest that if a CT course is implemented as a catapult for future integration, the course instruction areas should be clearly defined and focused on the essential skills of critical thinking. Similarly, the faculty members, particularly for effective integration, should be trained and well-versed in the concepts of CT. Hatcher (2006) wrote that for CT to be effective and not a slogan in higher education "the faculties must arrive at a shared understanding of what they mean by the phrase "CT." This is because one's conception of CT will determine what courses or materials are included in the attempt to enhance students' CT skills (Hatcher, 2000 as cited in Hatcher, 2006). The researchers agree with Hatcher (2006) that effective teachers and teaching can involve instruction on CT textbooks and foundations, but that those foundations and concepts are then applied to other courses, education, and areas of daily life.

It was also noted and implied in the research that key factors play a vital role in critical thinking skill learning and acquisition and assessment (Sousa, 2006; Wang \& Aamodt, 2011). Language, maturity, and motivation were key factors in this research. Language, as mentioned by several participants in the comments written on the assessment, was an issue. The students L1 of Arabic played a mediating if not perhaps impeding role on the 
results of the assessment which poses the question, if the test was offered in the participants L1, would the results have been different? The researchers questioned whether several of the unanswered items were due to lack of skill in CT or lack of English language proficiency. Offering the assessment in Arabic may have produced different results and would be a recommendation for further research. Further, as the assessment was voluntary and not based on any consequence, maturity with regard to spending adequate time and consideration on each item may have been a factor. Two hours were allotted for the pre and post-tests, but several participants returned the completed assessment after 1-1 $1 / 2$ hours. Maturity also plays a role when giving assessments, particularly assessments involving judgment and decisions and production of spontaneous extended responses. The average age of the participants was 19 years old. Based on several studies (Sousa, 2006; Wang \& Aamodt, 2011), often judgment and reliability does not become fully developed or reach maturity until around the age of 25 , which could have also affected the results particularly on sources/judging reliability, particularly considering the students may have not been exposed to CT skills training prior to the course.

This research also highlights a problematic reality of CT teaching and teaching in general in Saudi Arabia which is the limited metacognitive/cognitive strategy instruction and consequent use by the students. The participants performed better in all areas of the exam where evidence was given, connections were more obvious, and inferences easily made, in other words, the information was more explicitly provided. Monitoring their own thinking, making inferences on implied information, and judging based on critical analysis were simply lacking. Again, this is not a skill or strategy that can be learned in a course, but rather metacognition and cognition instruction represents an explicit constructive educational paradigm that should be integrated throughout the students' academic career in various courses and disciplines (Swartz et al., 2007; El Hassan \& Madhum, 2007; Israel, 2007). The lack of this foundational and educational background was obvious in this assessment and emphasized the paradox of a CT course without explicit and perhaps limited implicit meta/cognition strategy instruction. This is a key implication and recommendation for future revision of the CT course and overall curriculum.

Finally, this research illustrates that a critical thinking course produces marginal, but not significant, improvement in the key areas of CT. While the data shows that the students improved in the heavily taught area of argument analysis and that critical thinking was highlighted by the course, the results do not confirm that there is a significant improvement in the overall critical thinking skills of the participants. The researchers recommend further research in the area and a revised curriculum that integrates $\mathrm{CT}$ in all subjects and disciplines with an emphasis on the areas discussed and the underlying metacognitive and cognitive strategies. If the CT course is to be implemented due to program design constraints, then the course curriculum and teaching materials should also be revised and reviewed to reflect the needs of the learners in relation to viable CT development. In concurrence with Levine (2010), "teaching for critical thinking is an essential element of professional education — of educating professionals - since it promotes reasoned judgments under conditions of uncertainty, a hallmark of professionalism (Shulman, 2005)" (p.72).

\section{References}

Al-Hammadi, F. S. (2010). The Impact of Multimedia on Critical Thinking and Writing of Saudi Secondary School Students. Information Technology Journal, 9(1), 11-19. http://dx.doi.org/10.3923/itj.2010.11.19

Al-Seghayer, K. (2011). English Teaching in Saudi Arabia: Status, Issues, and Challenges. Riyadh, Saudi Arabia: Hala Print Co. ISBN 978-6030079254

AlWehaibi, H. U. (2011). The Effect of A CT Program on Developing College Students' CT Skills. Paper presented at the 3rd International Conference on Education and New Learning Technologies, Barcelona, Spain.

Behar-Horenstien, L. S., \& Niu, L. (2011, February). Teaching critical thinking skills in higher education: A review of the literature. Journal of College Teaching and Learning, 8(1), 25-40.

Beyer, B. (2001). Teaching Thinking Skills - Defining the Problem. In A. L. Costa (Ed.), Developing Minds: A Resource Book for Teaching Thinking. (pp. 35-41). Alexandria, VA: Association for Supervision and Curriculum Development (ACSD). ISBN-13:978-0-87120-379-3

Choy, \& Cheah. (2009). Teacher Perceptions of Critical Thinking Among Students and its Influence on Higher Education. International Journal of Teaching and Learning in Higher Education, 20(2), 196-204.

Cotter, E. M., \& Tally, C. S. (2009, December). Do CT Exercises Improve Critical Thinking Skills. Educational Research Quarterly, 33(2), 3-14. 
Cuban, L. (1993). How teachers taught: Constancy and change in American classrooms, 1800-1990 (2nd ed.) New York: Teachers College Press. ISBN-10: 0807732265 | ISBN-13: 978-0807732267

Egege, S., \& Kutieleh, S. (2004). Critical Thinking: Teaching Foreign Notions to Foreign Students. International Education Journal, 4(4), 75-85. ISSN-1443-1475

El Hassan, K., \& Madhum, G. (2007). Validating the Watson Glaser Critical Thinking Assessment. Higher Education, 54, 361-383. http://dx.doi.org/10.1007/s10734-006-9002-z

Facione, P. A. (1990). Critical thinking: A statement of expert consensus for purposes of educational assessment and instruction, "The Delphi Report." Millbrae, CA: The California Academic Press. ERIC Doc. NO.: ED 315423

Fisher, A., \& Scriven, M. (1997). Critical Thinking: Its Definition and Assessment. University of East Anglia: Edge press \& Centre for Research in CT.

Goodlad, J. (1984). A place called school: Prospects for the future. New York: McGraw-Hill.

Halper, D. F. (1993). Assessing the effectiveness of critical thinking instruction. The Journal of General Education, 42(4), 238-254.

Hatcher, D. L. (2006). Stand-alone vs. Integrated CT Courses. The Journal of General Education, 55(3-4), 247-272. http://dx.doi.org/10.1353/jge.2007.0002

Israel, S. (2007). Thinking Cognitively: Using Metacognitive Assessments to Create Individualized Reading Instruction. International Reading Association.

Leighton, J. (2006). Teaching and assessing deductive reasoning skills. The Journal of Experimental Education, 74(2), 109-136. http://dx.doi.org/10.3200/JEXE.74.2.107-136

Levine, T. H. (2010). Socializing Future Social Studies Teachers and K-12 Students: Whether, When, and Why. The Social Studies, 101, 69-74. http://dx.doi.org/10.1080/00377990903283973

Lloyd, M., \& Bahr, N. (2010). Thinking Critically about Critical Thinking in Higher Education. International Journal for the Scholarship of Teaching and Learning, 4(2), 1-16. ISSN 1931-4744 @ Georgia Southern University.

McPeck, J. (1981). Critical thinking and education. New York: St Martin's Press.

Moore, T. (2004). The critical thinking debate: How general are general thinking skills? Higher Education: Research and Development, 23(1), 3-18. http://dx.doi.org/10.1080/0729436032000168469

Nieto, S. (1999). What does it mean to affirm diversity? The School Administrator, 56(5), 32-34.

Nosich, G. (2009). Learning to Think Things Through: A Guide to Critical Thinking Across the Curriculum. Columbus, Ohio: Pearson Prentice Hall.

Paul, R. W., \& Elder, L. (2002). Critical thinking tools for taking charge of your professional and personal life. Toronto: Prentice Hall.

Perry, W. G., Jr. (1970). Forms of intellectual and ethical development in the college years: A scheme. New York, NY: Holt, Rinehart, and Winston.

Richmond, J. E. D. (2007). Bringing critical thinking to the education of developing country professionals. International Education Journal, 8(1), 1-29.

Scriven, M., \& Paul, R. (2003). Defining Critical Thinking: A draft statement prepared for the National Council for Excellence in Critical Thinking Instruction. Retrieved from http://www.criticalthinking.org/University/defining.html

Shulman, L. S. (2005, Summer). Signature pedagogies in the professions. Daedulus, 134(3), 52-59. http://dx.doi.org/10.1162/0011526054622015

Sievers, K. (2001). How do you know that...?. Critical Reasoning Handbook. Adelaide, Australia: Philosophy Department, Flinders University.

Simpson, E. (2002). The development of critical thinking in Saudi nurses: An ethnographical approach. Queensland University of Technology, Centre for Nursing, unpublished doctoral dissertation.

Sousa, D. (2006). How the Brain Learns (3rd ed.). Thousand Oaks, CA: Corwin Press.

Stratton, J. (1999). Critical Thinking for College Students. Lanham, MD: Rowman and Littlefield. 
Swartz, R. (2011). Dammam CT Study 2011. Newton, MA: National Center for Teaching Thinking (NCTT).

Swartz, R., Costa, A., Beyer, B., Reagan, R., \& Kallick, B. (2007). Thinking-based learning. Norwood, MA: Gordon.

Wang, S., \& Aamodt, S. (2011). Welcome to your Child's Brain: How the Mind Grows from Conception to College. New York: Bloomsbury, USA.

\section{Copyrights}

Copyright for this article is retained by the author(s), with first publication rights granted to the journal.

This is an open-access article distributed under the terms and conditions of the Creative Commons Attribution license (http://creativecommons.org/licenses/by/3.0/). 